\title{
LA RUTA DEL TRÁNSITO
}

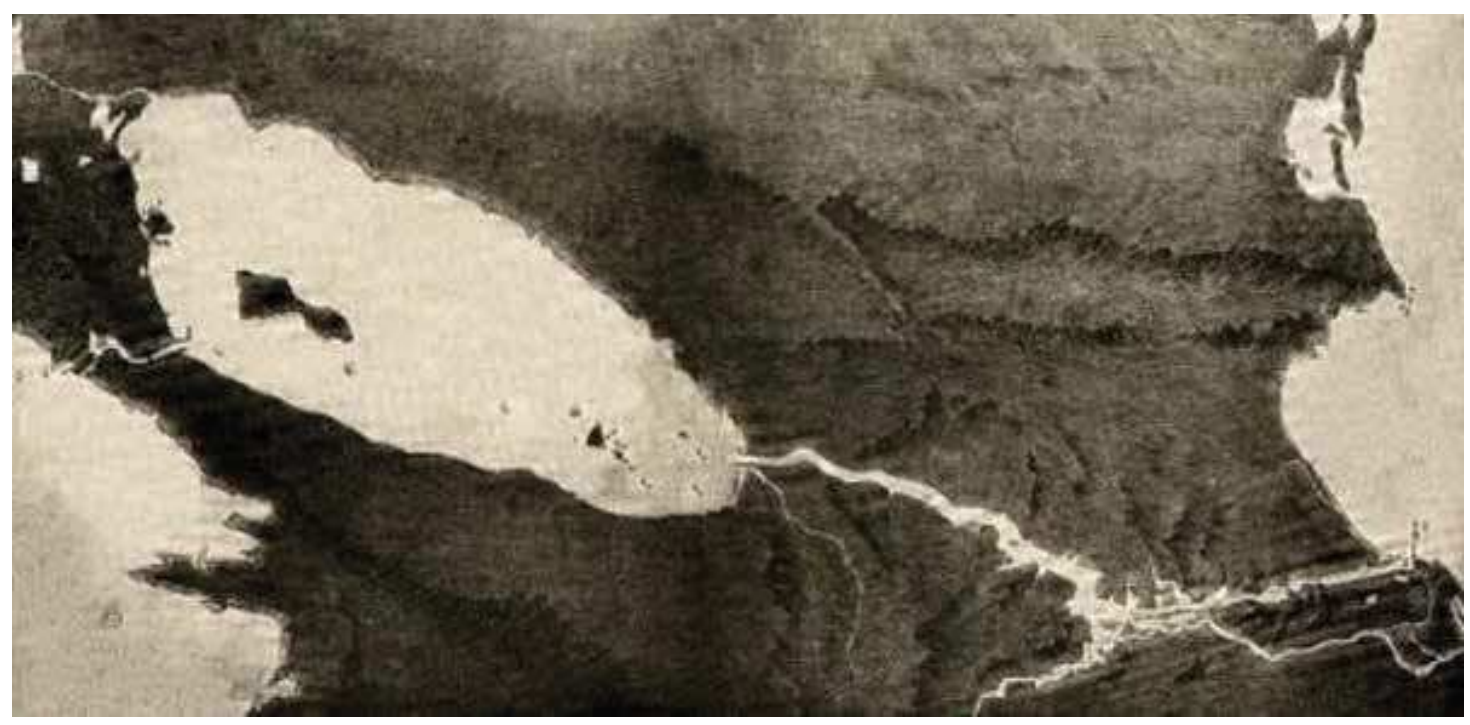

\section{Nota explicativa}

Se reproduce una nota del corresponsal y representante del periódico El Porvenir en el puerto de San Juan del Norte (hoy San Juan de Nicaragua). Este periódico tuvo una gran influencia en la vida nacional, después de la finalizada la Guerra Nacional. La frecuencia de salida era quincenal y desde su aparición en octubre de 1866, en sus páginas se convirtieron en un espacio público simbólico de gran importancia, al abordar de manera sistemática el tema de la rehabilitación de la ruta, conocida como "del Tránsito" (de un océano a otro, pasando por el lago Cocibolca y el río San Juan).

Esta vía de comunicación (Ruta del Tránsito) era de vital importancia para la economía del país durante gran parte del siglo XIX. De manera particular, cuando el gobierno de Nicaragua firmó contrato con empresarios norteamericanos para explotar, desde el punto de vista comercial, esa ruta. Las rentas que generaba esta concesión le representaba al Estado un monto sustantivo en su presupuesto anual.
Deigual manera, elcomerciointerno dependía mucho de esta ruta de comunicación, por las conexiones con el Caribe, la costa este de Estados Unidos, Colombia y Europa. Otra razón -no menos importante-era la posibilidad de sus autoridades y algunos sectores urbanos, de seguir soñando con la posibilidad de la construcción de un canal interoceánico.

Como lo documenta David Folkeman Jr. en su libro La ruta de Nicaragua (2001), luego de la crisis política que supuso la guerra civil y la invasión mercenaria, finalizada oficialmente en 1860, ---fecha en que Walker es fusilado en Honduras---, la ruta del Tránsito (concesión dada por el gobierno de Nicaragua al Comodoro Vanderbilt en 1851) representó un gran problema para los gobiernos de esa época. Una de las tareas a la que tuvo que abocarse los primeros gobiernos de los Treinta años Conservadores fue la revisión de los contratos y/o concesiones dadas antes y durante la guerra por los gobiernos anteriores. 
Otras de la dificultades que debieron afrontar estos gobiernos en este período, fue el tema del desvío del caudal de las aguas del río San Juan, a consecuencia de un fenómeno natural y otros problemas de manejo de la cuenca, hacia el cauce del río Colorado en territorio costarricense. Las autoridades gubernamentales y otros sectores de la economía nacional de ese entonces, no perdieron la esperanza en la rehabilitación de la ruta, tal como lo prueba el documento que la revista Humanismo y Cambio Social reproduce.

Los hechos posteriores demostraron que la ruta no podía ser rehabilitada con facilidad, dado que se requería, además de recursos, voluntad política de las partes involucradas, incluyendo a los inversionistas extranjeros. La compañía a la que se le otorgó los derechos de explotación, finalizada la guerra, abandonó el esfuerzo de rehabilitación y se retiró del país, generando una severa crisis económica, superada años después, con la inserción de la economía nacional por medio del café, al mercado internacional.

En la actualidad, el tema del canal por Nicaragua ha recobrado gran importancia en la agenda nacional y de manera particular, por las noticias de los avances que la compañía HKND de China, concesionaria de la construcción del canal (2013). Ante este escenario, se reproduce un texto de valor histórico, donde se constatan las dificultades enfrentadas -como se señaló con anterioridad-- por las autoridades de la época, durante la segunda mitad del siglo XIX, para el restablecimiento de la ruta acuática por el ríos San Juan, con fines de comercio y/o turismo. Sobre todo, la preocupación por la defensa de los recursos naturales y un territorio geográfico, hoy día en desarrollo y usufructuado por todos los nicaragüenses.

Título: Nuestra correspondencia de SAN JUAN DEL NORTE. El Porvenir. Rivas, $1^{\circ}$ de abril de 1867. Tomo $2^{\circ}$, pág.2; núm. $7^{\circ}$.

Señor Editor de "El Porvenir" de Nicaragua.

Señor mío.

Como he sido piloto en este istmo, he visto un tránsito floreciente. Dos o más vapores, algunos doce buques de guerra y muchos otros mercantes se veían con mucha frecuencia anclados, en la que diez años atrás era una de las mejores bahías del mundo. Todos sabemos las causas por las cuales esa bahía no es hoy lo que era entonces: la guerra intestina trajo a los filibusteros y estos las rivalidades de intereses de las compañías de vapores, arruinando la Compañía de Tránsito. Tales fueron las causas que hicieron al país retroceder espantosamente y sus consecuencias, principalmente la suspensión del Tránsito, causaron la pérdida de nuestra espléndida bahía.

Si diez años atrás se hubiera puesto coto a la voracidad del río Colorado, echándole solamente un dique, nos hallaríamos hoy como en aquella época. Muchos millares de testigos pueden encontrarse para probar que en 1851 el río Colorado se llevaba solamente una octava parte del río San Juan: hoy todos ven que es a la inversa. Si esto se hubiera remediado "en tiempo" no solamente se hubiera preservado nuestro puerto, sino que también la República hubiera dado largos pasos hacia el progreso ¿Quién puede negarlo? 
El público está al corriente de las altas y bajas y de cómo la Compañía de Tránsito ha luchado contra las poderosas intrigas de intereses rivales y otras dificultades que no es necesario mencionar, porque son bastante conocidas. Mientras tanto nosotros "pobres Micawbers"* hemos vivido con las esperanzas de mejores tiempos venideros.

Tantas desilusiones que hemos sufrido, justifican nuestra incredulidad. Y sinceramente creemos que si después de las dificultades que la Compañía ha tenido que vencer, de todo el capital consumido hasta el presente y el que aún están gastando, si no se le anima con concesiones más liberales de parte del Gobierno de Nicaragua, abandonará la obra disgustada, y retirará sus vapores de sus océanos ¿Qué será de nosotros? Nuestra propiedad que hoy vale veinte mil pesos, no valdrá otros tanto centavos. Si decimos esto, es por la simple, pero clara cuestión: ¿Intentará otra Compañía emplear su tiempo y su dinero con diez proyectos en oposición, teniendo océanos que navegar, millones de acres de tierra que poblar y millares de empresas en que emplear su dinero?

Sin embargo, no debemos perder la esperanza: liberalidad de parte de Nicaragua y actividad y capital de parte de la Compañía. Aún vemos el horizonte claro. Los preparativos que se están haciendo para el establecimiento de una línea de Tránsito cómoda y rápida, son tales, que podrían satisfacer a todos antes del año de 1868.

Estoy seguro de que será de mucho interés para los lectores de su periódico, algunos particulares más sobre lo que nosotros estamos haciendo aquí. Ya usted sabe que la gran máquina de profundizar [dragado] (que vale $\$ 40000$ ) ha llegado y se está trabajando de manera activa en su armado. Se construyó, como usted sabrá, bajo la superintendencia de Mr. S. Howard, ingeniero capaz y bien conocido, quien tiene la mayor confianza de que cuando se halle completa esta máquina, será muy competente para hacer desaparecer todas las dificultades de la bahía y el río, asegurar entrada y anclaje seguro en aquella y fácil navegación en éste. Ya usted ve que una vez vencidas esas dificultades, desaparecerán con ellas todos los obstáculos para un buen tránsito por el río o se volverán insignificantes.

El vaporcito está ya listo para recibir la maquinaria y las calderas ya están aquí. Se echará al agua dentro de pocos días, y muy pronto estará listo para iniciar su trabajo. Tiene 70 pies de largo y 22 de ancho y 8 de profundidad de casco. Está construido enteramente de pino amarillo y de gran fuerza de duración. Su maquinaria es del mejor material y de mucho poder. Dotada de cualidades semejantes, confío, señor mío, que tenemos razón para creer que será un don precioso, tan largo tiempo deseado, para el porvenir de las Repúblicas de Nicaragua y de Costa Rica.

Mr. Howard ha hecho un reconocimiento minucioso del puerto y de la barra. El hecho de contener arena movediza, considerado hasta por algunos como una desventaja, para este técnico, puede tornar en ventaja, estudiando la acción de las corrientes sobre ella. También confía en que rectificando y profundizando el canal del río, adquirirá agua suficiente para la navegación de los vaporcitos en toda estación. A este respecto, es de notarse que ciertos habitantes de los bancos de la parte baja del río San Juan, tanto del lado de Costa Rica como del de Nicaragua, estén echando árboles en el canal del río, al mismo tiempo que la Compañía está gastando miles de pesos para quitar semejante obstrucciones. Apenas puede concebirse esta acción como una política suicida. Esto indica que existen hombres ignorantes 
de sus propios intereses. El gobierno de Nicaragua y el gobierno local de San Juan del Norte, debían prontamente hacer cesar semejante procedimiento que de manera complaciente han permitido por mucho tiempo.

Se garantiza que la maquinaria cavará diariamente un canal de 200 yardas de largo, 20 pies de ancho y 4 de profundidad. Esto dará a usted una idea de la prontitud con que desaparecerán nuestros bancos de arena. En esa proporción pueden hacerse las mejoras del río, desde el río Colorado al puerto en cuatro meses: supongamos cuatro meses más para trabajar en la barra, mientras se cierra el Colorado al mismo tiempo. Y yo lo convido a usted para un banquete de la noche buena a bordo de un vapor o buque de guerra. Yo brindaré: Tenemos PUERTO (mayúscula en el original).

Supongo que nadie daría crédito a los rumores esparcidos por un criminal fugitivo de que Costa Rica había tomado el Castillo, cuando por el contrario, ellos se hallan en la disposición más fraternal con respecto al tránsito y a Nicaragua. En prueba de ello, doy a usted los siguientes e importantísimos informes: la Compañía Centroamericana de Tránsito despachará inmediatamente el vapor "Cora" o Capitán Parmely al río San Carlos, para averiguar hasta donde es navegable por los vaporcitos chatos de la Compañía. El gobierno de Costa Rica habiendo abierto ya la navegación del río, por un decreto, se propone terminar de una vez la cuestión.

Una comisión, con el Capitán Merry, el agente general de la Compañía, se dirigirán río arriba en el "Cora". Si el gobierno de Costa Rica halla que el río San Carlos se presta a la navegación por vapor, tendrá un doble aliciente para terminar el camino proyectado de San José a dicho río, obteniendo así una vía mucho menos costosa para los productos del país, que la de Panamá. Esperamos dar un informe completo del viaje hecho en el "Cora" para el próximo número. Confiamos en que tendrá buen éxito. Tanto este asunto como otros sobre la ruta del tránsito (por el río San Juan) parecen indicar una prosperidad creciente de negocios que ejercerán una influencia favorable sobre Nicaragua y crearán las relaciones comerciales más útiles con Costa Rica.

Aquí tuvimos la visita de su Presidente (Tomás Martínez) y acompañamiento (su séquito). Me parece que debe haber quedado satisfecho de nuestra situación. Nosotros contribuimos con la octava parte de todas las rentas (del país) y lo hacemos con gusto, porque los negocios los manejamos por nosotros mismos, con particular economía, de manera ágil y de fácil despacho para el público y el comercio.

Tenemos una buena policía y un buen sistema judicial y la experiencia prueba que nuestro sistema produce buenos efectos (En San Juan del Norte) ¿Por qué usted y su gobierno (recrimina al gobierno de Martínez) no abandonan su antiguo sistema que pertenece a la edad media donde tuvo su origen? He tenido frecuentes conversaciones con el Sr. Guzmán, su futuro Presidente y debo decir, que hallé en él un hombre de ideas más adecuadas a los tiempos presente. Creo que él será uno de los mejores Presidentes de Nicaragua de los últimos tiempos, si la gente abandona la vida de caprichos de partido y le ayuda en su carrera. Si sus proyectos se llevan adelante, impulsará a Nicaragua hacia el progreso. 
Deseo a usted buen éxito para su periódico. Pero si éste saliera en ediciones separadas en inglés y español, seguramente prosperaría más. Es necesario su adelanto y el de todas las grandes empresas, de minas, Tránsito (la de vapores), manufacturas, canales y ferrocarriles, seguro que tendrán un gran interés en mantener su periódico a toda costa.

En [la] primera oportunidad le enviaré mis noticias. Sírvase mandarme la serie completa de "El Porvenir", porque tengo algunos nuevos suscriptores cuyos nombres he hecho registrar en su agencia.

Su servidor---MICAWBER (seudónimo)

*Palabra que puede hacer referencia a Dickens o una condición meteorológica 